\title{
Rosario Castellanos, Feminista A PARTIR DE SUs PROPIAS PALABRAS
}

\author{
Rosario Castellanos, Feminist in her Own Words
}

\author{
Marta Lamas
}

Resumen: A partir del análisis de sus escritos periodísticos, en este artículo se recupera a Rosario Castellanos como una pionera intelectual del feminismo mexicano. Se defiende la idea de que en sus artículos periodísticos se plasma con fuerza, claridad y lucidez un pensamiento feminista moderno, que gira principalmente en torno a los efectos del mandato cultural de la feminidad, haciendo un aporte a la crítica de la situación de las mujeres mexicanas. En efecto, Castellanos rechaza el victimismo, reivindica la necesidad de terminar con la autocomplacencia femenina y propone que las mujeres se responsabilicen de sus vidas, madurando y puliendo ideas que todavía hoy en día tienen vigencia y radicalidad notables.

Palabras clave: Rosario Castellanos, feminismo, movimiento de liberación femenina, comportamiento cultural, periodismo, cultura mexicana.

Abstract: Based on an analysis of the journalistic reporting of Rosario Castellanos, this article rescues (o- highlights) her importance as a pioneering intellectual of Mexicanfeminism. It defends the idea that her forceful, clear, and lucid reports demonstratemodern feminist thinking, turning on concepts of the effects of cultural mandates on female behavior, and supporting a critical look at the condition of women in Mexican society. In effect, Castellanos rejects the notion of victimization, instead stressing the need for women to stop being self-complacent; she proposes that women take responsibility for their own lives, thus developing and polishing ideas that are notably relevant and even radical today.

Keywords: Rosario Castellanos, feminism, women's liberation movement, cultural behavior, journalism, Mexican culture.

\footnotetext{
Marta Lamas. Doctora en Antropología del Instituto de Investigaciones Antropológicas de la Universidad Nacional Autónoma de México Profesora investigadora de la Coordinación de Humanidades de la Universidad Nacional Autónoma de México, adscrita al Centro de investigaciones y Estudios de Género. Temas de especialización: mandatos culturales de género; feminismo, trabajo y subjetividad. Correo electrónico: martalamas@gmail.com.
}

Enviado a dictamen: 15 de noviembre de 2016

Aprobación: 16 de marzo de 2017.

Revisiones: 1 . 
$\mathrm{R}$ osario Castellanos fue una gran feminista. ${ }^{1}$ La mayoría de quienes lo afirmaron antes, lo hicieron a partir del análisis de la rica obra literaria de esta chiapaneca universal; y hay quienes lo concluyen con base en la tesis de Maestría en Filosofía que la autora presentó a los 25 años de edad, el 23 de junio de 1950, tres años antes de que las mexicanas obtuvieran el derecho de votar. Elena Poniatowska asegura que con esa tesis, titulada "Sobre cultura femenina", Castellanos "establece el punto de partida intelectual de la liberación de las mujeres en México" (Pacheco, 1974: 7). ${ }^{2}$ Es de notarse que la joven Rosario escribió su tesis sin haber leído El segundo sexo de Simone de Beauvoir, publicado en París un año antes. ${ }^{3}$ La historiadora Gabriela Cano (2012) considera que la tesis es un claro ejemplo de lo que Mary Louise Pratt (2000) llama el "ensayo de género", o sea, una reflexión crítica que discute el estatuto de las mujeres en sociedad y que confronta la pretensión masculina de monopolizar la autoridad intelectual. Medio siglo después de presentada la tesis, el Fondo de Cultura Económica la publicó a instancias de Cano, con un prólogo de la historiadora que ubicaba el momento histórico en que se presentó la tesis y sus influencias intelectuales.

"Sobre cultura femenina" es una tesis sólida desde un punto de vista académico. En ella Castellanos desmonta eficazmente el pensamiento machista y androcéntrico de diversos filósofos y escritores en torno a lo que han dicho sobre las mujeres. Con su célebre ironía, ${ }^{4}$ Castellanos expone en qué consiste la cultura femenina, y el salón de examen se "inunda de risas" (Cano, 1992: 253). Algunas personas no captan la sutileza de su crítica, y piensan que Rosario avala las consideraciones machistas sobre la inferioridad de las mujeres. iCraso error! Luego de desnudar el sexismo y la misoginia de varios autores, ella señala que no le queda más remedio que recurrir a "la propia tentativa, a la propia labor, al propio hallazgo" (Castellanos, 2005: 79). Rosario dice que le intriga que:

La mayor parte de las mujeres están muy tranquilas en sus casas y en sus límites sin organizar bandas para burlar la ley. Aceptan la ley, la acatan, la respetan. La consideran adecuada. ¿Por qué entonces ha de venir una mujer que se llama Safo, otra que se llama Santa Teresa, otra a la que nombran Virginia Woolf, alguien (de quien sé en forma positiva que no es un mito como podrían serlo las otras y lo sé porque la he visto, la he oído hablar, he tocado su mano) que se ha bautizado a sí misma y se hace nombrar Gabriela Mistral, a violar la ley? (2005: 84).

Ella no quiere, "como hacen las y los feministas, defenderlas a todas mencionando a unas pocas" (2005: 84). Por eso, a la pregunta que ella misma se formula: “iHay un modo de pensar específico de nosotras?" (2005: 86), responde: "Los más venerables autores afirman que es una intuición directa, oscura, inexplicable y, generalmente, acertada. Pues bien, me dejaré guiar por mi intuición" (2005: 86).

Esa tarea que Castellanos emprende con eso que califica de "intuición", la acompaña de un ejercicio irónico de erudición, y así coincide con lo que también señala Simone de Beauvoir: la diferencia que vemos socialmente entre las mujeres y los hombres no se deriva de la biología o de una incapacidad congénita, sino de un encauzamiento distinto de la energía y el espíritu. Para los varones, la producción de cultura es la vía para trascender en el mundo, mientras que la maternidad lo es para las mujeres. Su perspicacia feminista guía su pluma y la lleva a elaborar una reflexión que gira principalmente en torno a los efectos del mandato cultural de la feminidad en las mujeres. Rosario Castellanos escribe mucho sobre mujeres, sobre sus emociones, sobre cómo viven el amor, el matrimonio, la maternidad, la soledad; y, en sus textos, ella recuerda su infancia de soledad, rechazo y discriminación, exhibe sus heridas amorosas y expresa su anhelo de maternidad. La escritora aborda así los temas centrales de la crítica feminista. Junto con las mujeres que pueblan su obra literaria — novelas, cuentos y poesías - y sus ensayos, Castellanos analiza la obra de otras autoras, y las vuelve figuras cercanas y entrañables. Coincide con De Beauvoir en que el estudio de los mitos en una cultura es una vía para decodificar las actitudes sociales ante las mujeres, y analiza críticamente las tres figuras 
míticas de la mujer en México: la Malinche, la Virgen de Guadalupe y sor Juana (Castellanos, 1998c).

Todo autor es la suma de sus obsesiones. La vida, las pasiones y los dolores de Rosario Castellanos resuenan en sus poemas, en sus narraciones literarias y en sus colaboraciones periodísticas. Según cierta crítica literaria, lo que distingue la escritura de Rosario Castellanos es que integra una intelectualidad femenina con una textualidad femenina (Zamudio y Tapia, 2006). Maureen Ahern apunta que Castellanos creó un discurso intrínsecamente femenino (1988: 36), y que la forma en que nuestra escritora aborda su tratamiento de las mujeres en México es no sólo una vía eficaz para explicar los mitos culturales, sino también para escribir un tipo nuevo de literatura (1988: 43). Este proceso de escribir asumiéndose como mujer, sin resbalar al estereotipo, no fue fácil ni indoloro pues, como señaló Carlos Monsiváis, ella tuvo que "librar un combate explícito por su derecho a no confinarse en una literatura profesionalmente 'femenina'” (1992: 321). El autor considera que, a partir del sarcasmo y la distancia crítica, Rosario “destruye memorablemente muchas de las trampas y prisiones de la 'sensibilidad femenina' y escribe una poesía admirable, despojada de cualquier velo retórico, directa, crítica... una poesía claramente autobiográfica, pero no poesía “confesional”' (1992: 322).

Según Elena Poniatowska (s.f.), Rosario protesta del único modo que sabe: escribiendo; y así se va convirtiendo en una gran poeta y una narradora impresionante. Los amplios estudios en torno a sus textos confirman esa justa apreciación. Pero además de su espléndida obra literaria, Rosario Castellanos escribe en periódicos y revistas, y precisamente ahí se encuentran diáfanos ejemplos de su feminismo. Ella registra con agudeza eso que el feminismo contemporáneo denomina la construcción del "género" (Lamas, 2016); o sea, ese conjunto de creencias culturales sobre "lo propio" de las mujeres y "lo propio" de los hombres, que se expresa en "usos y costumbres", y lo critica de manera nada complaciente. Gracias a la valiosa labor de Andrea Reyes al investigar y recopilar sus escritos periodísticos, hoy contamos con abundantes e indiscutibles pruebas de su feminismo. Reyes buscó, desenterró y, como ella misma dice, "rescató" un amplio número de documentos que no habían sido incluidos en ninguna de las antologías y bibliografías previas: muchos de los que Castellanos publicó en Excélsior y otros más desperdigados en suplementos y revistas literarias. Al inicio de su labor, Reyes buscaba alrededor de cien ensayos, y al final encontró 338 que, sumados a los 179 ya publicados en antologías, hacen de la producción de Rosario Castellanos un total de 517 artículos periodísticos. ${ }^{5}$ Esta recolección en tres tomos —publicados en 2004, 2006 y 2007- congrega 399 textos bajo el título Mujer de palabras. Artículos rescatados de Rosario Castellanos. Nunca dejaré de agradecerle a Andrea Reyes su valiosísimo trabajo pues permite visualizar este aspecto menos conocido del pensamiento feminista de Rosario Castellanos. El título que Reyes le puso a su compilación, Mujer de palabras, lo tomo del poema "Pasaporte":

¿Mujer de ideas? No, nunca he tenido una. Jamás repetí otras (por pudor o por fallas mnemotécnicas)

¿Mujer de acción? Tampoco

Basta mirar la talla de mis pies y mis manos.

Mujer, pues, de palabra, No, de palabra no,

Pero sí de palabras,

muchas, contradictorias, ay, insignificantes, sonido puro, vacuo, cernido de arabescos, juego de salón, chisme, espuma, olvido. Pero si es necesaria una definición para el papel de identidad, apunte que soy mujer de buenas intenciones y que he pavimentado un camino directo y fácil al infierno (Castellanos, 1998b: 221).

Ahora bien, sin olvidar que el feminismo de Rosario Castellanos se expresa en toda su obra, en su poesía y literatura, destaca lo manifiesto en sus potentes artículos de crítica cultural y política. Ahí, ella mezcla su preocupación por la marginación de las mujeres, por su sumisión a conductas autodevaluatorias, por la enajenación de una maternidad mistificada y 
chantajista, y por las consecuencias negativas de la abnegación, con escenas de su propia vida cotidiana, en relatos divertidos donde se burla de sí misma.

Deslumbra la lucidez con que analiza la condición de las mujeres y las expresiones de eso que hoy calificamos como el mandato cultural de la feminidad. Tal lucidez recorre toda su obra y, como bien señaló Margarita García Flores (1979), es la materia misma de su vida. Justo esa lucidez la lleva a interpretar, sin conmiseración alguna, su propia conducta y la de sus congéneres femeninas.

Eduardo Mejía (1998) relata que Raúl Ortiz y Ortiz, uno de los mejores amigos de Rosario, publicó El eterno femenino a la muerte de Castellanos. Ese texto generó mucha incomodidad, pues:

[...] en pleno auge del feminismo, pinta unas mujeres conformistas, a lo largo de la historia, con la supremacía masculina, impulsoras del machismo, contentas de no tomar decisiones, fascinadas de que las elogien por su físico y no por sus méritos, encantadas con las torturas a las que deben someterse para agradar al macho (Mejía, 1998: 9).

No es de extrañar la incomodidad y rechazo que esa obra suscitó entre quienes asumen el "mujerismo". ${ }^{6}$

Aunque El eterno femenino reúne muchas de las críticas que Rosario ya venía realizando, su feminismo es más frontal en sus artículos periodísticos. En agosto de 1968 publica "La mujer iser inferior?" (Reyes, 2006: 153-155), donde describe la feminidad como una forma de violencia simbólica. Se recordará que la violencia simbólica es la que las propias personas se aplican a ellas mismas. Según Bourdieu, es "violencia amortiguada, insensible, e invisible para sus propias víctimas, que se ejerce esencialmente a través de los caminos puramente simbólicos de la comunicación y del conocimiento" (2000: 12). Rosario Castellanos percibe ese ejercicio de violencia de las propias mujeres contra sí mismas y señala:

[...] hasta qué punto se ha puesto en manos de las mujeres la defensa de un tipo de valores que las perjudican y las colocan en situación de inferioridad, y de cómo ellas han cumplido con un celo digno de mejor causa el papel de guardianas de la pureza de la tradición (Reyes, 2006: 153).

Nuestra escritora denuncia la manera en que la cultura va haciendo que el varón se convierta en victimario y la mujer en víctima. Habla de la rivalidad entre la madre y la hija, de la ausencia de solidaridad entre mujeres, de la individualidad irreductible del narcisismo femenino. Todas esas cuestiones siguen vigentes, sin asumirse ni resolverse entre la mayoría de nuestras conciudadanas, incluso entre las propias feministas.

Además de sus duras apreciaciones sobre la forma en que tradicionalmente se asume la feminidad tradicional, desde muy temprano Rosario Castellanos habla del feminismo, de las feministas, de la emancipación femenina e incluso se autonombra feminista. Doy algunos ejemplos. Con 32 años de edad —en "Presencia de Concha Urquiza”, de 1957-, analiza la obra poética de la michoacana y suelta la idea de que: "en México la protesta femenina no ha sido nunca descarada y franca", para además señalar: "No esperemos pues encontrar proclamas rebeldes de feministas emancipadas con deseos de hacer prosélitos" (Reyes, 2004: 70).

Se requiere de un amplio libro para dar cuenta de la cantidad de señalamientos, guiños y críticas feministas que se encuentran en los artículos periodísticos reunidos en Mujer de palabras (Reyes, 2004, 2006 y 2007). En estas páginas voy a referirme sólo a algunos muy significativos. Rosario empieza a escribir en Excélsior en junio de 1963, y el 7 de diciembre de ese año publica una reseña de un estudio sobre la Personalidad de la mujer mexicana, ${ }^{7}$ que titula "Feminismo a la mexicana" (Reyes, 2004: 247-250). En ese texto conjuga muchas de las preocupaciones feministas a las que dedicará su atención una y otra vez: la diferencia del trato familiar hacia las niñas y los niños, el desinterés por la educación de la niña, el terror a la soltería, la maternidad como realización social y el rechazo de los varones, que describe así: "la mujer que intenta ejercitar su voluntad, hacer uso de su inteligencia, realizar una vocación, sabe que corre un 
riesgo: la soledad. Los hombres huirán de ella por sus complejos" (Reyes, 2004: 249). Sin embargo, la crítica más dura que formula no se dirige a los varones, sino a las mujeres. Ella remata preguntando:

¿Quién es tu peor enemigo? El de tu oficio, dice el refrán. Y el oficio de mujer en México, que quizás es uno de los más duros, cuando ha pretendido un equilibrio mayor de las relaciones entre los sexos, ha encontrado la resistencia más enconada, no entre los hombres, sino entre las mismas mujeres. Ellas, aun las emancipadas, las creadoras, no aprovechan sus medios de expresión para una rebeldía franca sino apenas para un débil gemido, cuando no para predicar la abnegación, la humildad y la paciencia. Todavía los "hombres necios que acusáis" de Sor Juana sigue siendo nuestra protesta más audaz. Habría que preguntarse por qué el feminismo, que en tantos otros países ha tenido sus mártires y sus muy respetadas teóricas, en México no ha pasado de una actitud larvaria y vergonzante. ¿Es masoquismo? ¿Es temor al ridículo? (Reyes, 2004: 250).

¡Esto lo escribe en 1963!, cuando todavía no se perfilaba siquiera lo que vendría a ser la segunda ola del feminismo, también llamada "movimiento de liberación de la mujer". Durante varios años Castellanos publica artículos filosos sobre escritoras y acontecimientos políticos y culturales, dejando caer sus señalamientos feministas. Por ejemplo, en "Un bosquejo de Balaguer: las gobernadoras”, de 1966, relata el "caso insólito" del presidente dominicano a quien califica de "esa rarísima ave caribeña que abre, de par en par, las puertas de la vida pública para que tengan acceso a ellas quienes tradicionalmente habían permanecido, como con la pierna quebrada, en casa" (Reyes, 2004: 552). Y ante los nombramientos de gobernadoras de las provincias, que otorgó este político a mujeres que habían participado activamente en su campaña electoral, Rosario exclama: "¿Qué haremos las feministas autóctonas?" (2004: 552).

De 1969 sobresalen dos artículos — "El queso y la ratonera: la emancipación femenina” (Reyes, 2006:
325-328) y "Feminismo 1970: curarnos en salud" (2006: 378-381) - en los que critica tanto los esquemas de la cultura como la acción de algunas feministas. En el primero se burla ácidamente de la demagogia política sobre la "emancipación”, y dice que:

[...] la emancipación significa hasta ahora, fundamentalmente, no una hazaña de la voluntad, no una prueba de la aptitud, no un alarde de la inteligencia sino algo más difícil y más peligroso que todo eso: una proeza del equilibrio. Porque la mujer mexicana tiene que ser, de manera simultánea y ubicua, el cimiento inconmovible del hogar y uno de los pilares de la fábrica, de la oficina, del aula. Tiene que dedicar su atención — con la misma intensidadal cuidado físico, moral e intelectual de sus hijos en proceso de desarrollo y a los problemas que le plantea su trabajo, su participación en la vida comunitaria, su examen de la realidad política en la que se supone que es un factor determinante. Tiene que dividir su tiempo entre la consagración al esposo del que, según la fórmula sacramental, es compañera y no sierva. Por lo tanto debe actuar como interlocutora, como caja de ahorros, como objeto decorativo en las reuniones sociales, amén de proporcionar la ropa limpia, de mantener los botones en su lugar, de presentar la mesa puesta y cumplir, integra y satisfactoriamente, los deberes conyugales que por sabidos se callan (Reyes, 2006: 325-326).

En el segundo analiza los primeros grupos del nuevo feminismoen Estados Unidos, con muchos señalamientos acertados; solamente retomo aquel donde sostiene que estas feministas:

En su lucha rompen la imagen seductora que de la feminidad ha elaborado nuestra época (y que en esto se asemeja a todas las épocas anteriores). Destruyen tabúes que no han perdido aún el prestigio de lo sagrado y arrostran el riesgo de ser excesivas, de ser injustas y, sobre todo, de ser impopulares entre aquellas que deben constituir el núcleo de sus seguidoras (Reyes, 2006: 380). 
¡Hay que leerlos completos!

En 1970, en una nota que titula "Casandra de huarache: la liberación de la mujer, aquí" (Reyes, 2006: 561-564), Rosario se responde sobre la ausencia en México de feministas. El argumento es genial. Autonombrándose como profetisa autóctona, toma como referencia la gran marcha que se llevó a cabo el miércoles 26 de agosto de 1970 en varias ciudades de Estados Unidos, para celebrar los cincuenta años del voto obtenido por las ciudadanas norteamericanas en 1920, y formula una valoración sobre la ausencia de movilización feminista en nuestro país. Con su registro, se adelanta dos semanas al reportaje que otra pionera del feminismo mexicano, Marta Acevedo, publicó en "La Cultura en México", con una pequeña introducción de Elena Poniatowska. ${ }^{8}$ El artículo de Castellanos inicia con el relato de la marcha, para seguir con un análisis político del feminismo en Estados Unidos, comentando la gama de las reacciones en México: "desde el choteo burdo y aún los juegos de palabras procaces, hasta el desgarramiento de las vestiduras ante este nuevo signo apocalíptico que anuncia la decadencia y quizá la muerte de nuestra cultura y de nuestra civilización" (Reyes, 2006: 562). Luego señala que todos esos comentarios tienen una característica común: se refieren a ese movimiento de liberación de la mujer en Estados Unidos como si estuviera "ocurriendo en el más remoto de los países o entre los más exóticos e incomprensibles habitantes del menos explorado de los planetas. Esto es, como si lo que está aconteciendo del otro lado del Bravo no nos concerniera en absoluto" (2006: 563); y finaliza con una demoledora crítica a las mujeres de su clase social:

A mí no me gusta hacerla de profetisa pero esta es una ocasión en que se antoja fungir como tal. (Aparte de que la profecía es uno de los pocos oficios que se consideran propios para señoras histéricas como su segura servidora). Y yo les advierto que las mujeres mexicanas estamos echando vidrio acerca de lo que hacen nuestras primas y estamos llevando un apunte para cuando sea necesario. Quizá no ahora ni mañana. Porque el ser un parásito (que es eso lo que somos, más que unas víctimas) no deja de tener sus encantos. Pero cuando el desarrollo industrial del país nos obligue a emplearnos en fábricas y oficinas, y a atender la casa y los niños y la apariencia y la vida social y, etcétera, etcétera, etcétera, entonces nos llegará la lumbre a los aparejos. Cuando desaparezca la última criada, el colchoncito en que ahora reposa nuestra conformidad, aparecerá la primera rebelde furibunda (Reyes, 2006: 563-564).

Precisamente uno de los impulsos en la movilización política de las mujeres que conformaron la segunda ola feminista fue la confrontación con el trabajo del hogar, sobre todo para quienes ya trabajaban fuera de casa. Si el movimiento feminista tuvo tanta fuerza en Estados Unidos y en Europa fue, indudablemente, porque las mujeres como Rosario Castellanos —universitarias, profesionistas o funcionarias - no tenían empleadas del hogar. Así, la confrontación con la carga de ocuparse de las labores del hogar fue un disparador del activismo entre esas mujeres de clase media. En su conclusión - "Cuando desaparezca la última criada, el colchoncito en que ahora reposa nuestra conformidad, aparecerá la primera rebelde furibunda" - condensa el análisis político que elabora el nuevo feminismo sobre la importancia del trabajo llamado doméstico (Costa y James, 1975). Al marcar la importancia política de ese trabajo "invisible" coincide con Marta Acevedo (1995a), cuyo reportaje en el suplemento cultural de la revista Siempre! funcionó como un dispositivo alrededor del cual un grupo de mujeres empezó a reunirse con el modelo del pequeño grupo de autoconciencia para discutir el tema.

Este primer grupo de la segunda ola feminista en México salió a las calles con el nombre de Mujeres en Acción Solidaria el 10 de mayo de 1971, en una protesta por la celebración del Día de la Madre. ${ }^{9}$ Pero, una vez más, Rosario Castellanos se adelantó a esa expresión pública, pues su discurso de tres meses antes - 15 de febrero- se convirtió en el punto de referencia de ese nuevo feminismo en México. Ese día, el PRI conmemoraba el Día Nacional de la Mujer, y se desmarcaba del festejo del 8 de marzo, 
Día Internacional de la Mujer. Rosario Castellanos pronunció un discurso en el Museo Nacional de Antropología frente a un numeroso grupo de mujeres destacadas y funcionarias, junto al presidente Luis Echeverría y su esposa, María Esther Zuno. ${ }^{10}$ Hoy sus palabras la consagran como la indudable precursora intelectual de la liberación de las mujeres mexicanas. Unos días antes, el presidente Echeverría había hecho que la nombraran embajadora en Israel por la gran admiración que provocaba en la pareja presidencial. Ella comunicó públicamente su designación cinco días después del acto en el museo en su columna editorial de Excélsior, con esa actitud burlona y menospreciativa que la caracterizó: "de pronto izas! que me nombran embajadora” (Reyes, 2006: 661). El discurso que cimbró a los asistentes se publicó el 21 de febrero en el suplemento "Diorama de la Cultura" de Excélsior, un día después del artículo donde contaba que había sido nombrada embajadora.

En ese discurso, titulado "La abnegación: una virtud loca" (Reyes, 2006), encontramos a una feminista que ha madurado y pulido ideas que venía germinando desde los años cincuenta. Eran ya cuatro lustros de una aguda observación de su entorno, a la que se agregaba una intensa reflexión y una labor escritural incesante, y todo ello acompañado de su consabida lucidez, que cuajaron en unas palabras que conmovieron o irritaron profundamente a las presentes. En sus líneas plantea, de manera radical, un vínculo entre la situación de las mujeres, el mandato de la feminidad y los problemas nacionales. Su estrategia es impecable. Empieza señalando que: "La aportación de la mujer a la cultura en México ha sido muy importante si la consideramos únicamente desde el punto de vista cualitativo" (Reyes, 2006: 663), o sea, el genio de sor Juana logra equilibrar el raquítico panorama de las aportaciones femeninas. Pero como no son las excepciones las que sirven para dar cuenta del nivel cultural de la población, sino las estadísticas, ofrece una radiografía de la desoladora situación educativa de las mexicanas, incluso de las profesionistas. Ella señala que ese patético fenómeno debe tener una explicación, que no es la "de los antifeministas que decretan una inferioridad atribuible al sexo" (Reyes, 2006: 664), y propone otra explicación que despliega con gracia y agudeza.

Ante el interrogante sobre la razón por la cual es patente la ausencia de mujeres destacadas, Castellanos responde que: "El sexo, lo mismo que la raza, no constituye ninguna fatalidad biológica, histórica o social. Es sólo un conjunto de condiciones, un marco de referencias concretas dentro de las cuales el género humano se esfuerza por alcanzar la plenitud en el desarrollo de sus potencialidades creadoras" (Reyes, 2006: 664). Esto es justo lo que hoy sostiene la gran mayoría de investigadores y científicos.

Para transmitir la audacia y la brillantez de sus palabras cito textualmente varios párrafos del discurso.

El primer argumento que acude a los labios de las feministas más airadas que reflexivas —al comparar su situación propia con la del hombre- es la exigencia de la igualdad. Una exigencia que en tanto que es metafísica, lógica y prácticamente imposible de satisfacer, proporciona un punto de partida falso y arrastra consigo una serie de consecuencias indeseables. Además de que, en última instancia, no es más que un reconocimiento del modelo de vida y de acción masculinos como los únicos factibles, como la meta que es necesario alcanzar a toda costa. No. Si nos proponemos construir un feminismo auténtico pero, sobre todo, eficaz, tenemos que partir de otros postulados, el primero de los cuales sería la investigación acuciosa, el conocimiento lo más exacto y puro que pueda alcanzarse del complejo de cualidades y defectos, de carencias y de atributos, de aspiraciones y limitaciones que definen a la mujer. Esta investigación va a conducirnos a un descubrimiento muy importante: el de que no existe la esencia de lo femenino. Porque lo que en una cultura se considera como tal, en otra o no se toma en cuenta o forma parte de las características de la masculinidad. Pero entonces, si no existe la esencia de lo femenino tendremos que admitir que lo que existe son las encarnaciones concretas de la feminidad (Reyes, 2006: 664). 
Esta postura antiesencialista tiene coincidencias claras con el pensamiento de Simone de Beauvoir, y prefigura la postura que posteriormente asumirá la mayoría de las autoras feministas.

Rosario Castellanos aborda cuestiones centrales de hoy como el debate entre los feminismos que discuten sobre si hay que luchar por la igualdad o por la equidad. También acota que, en la problemática social, se encuentra una gran variedad de mujeres, por los diferentes estratos económicos, culturales y temporales existentes. Así desmonta el consabido recurso de hablar de "la mujer" y plantea que hay que distinguir entre las diversas situaciones y desarrollos de las mujeres. Ella contrapone algunos ejemplos, que van desde la indígena que pastorea ovejas a la estudiante de la Facultad de Ciencias, de la situación inhibida de la muchacha provinciana a la desenvuelta de la deportista, de la sirvienta que acaba de descubrir la licuadora a la de la azafata que recorre rutinariamente el mundo. Y subraya:

Pero todas están ligadas entre sí, por lo pronto, de las siguientes maneras: todas están sujetas a los derechos y obligaciones de una misma legislación; todas han heredado el mismo acervo de tradiciones, de costumbres, de normas de conducta, de ideales, de tabúes; todas están dotadas del mismo grado de libertad como para reclamar sus derechos si se les merman; como para cumplir o no con las obligaciones que se les imponen; como para optar entre la repetición de los usos ancestrales o la ruptura con ellos; como para aceptar o rechazar los arquetipos de vida que la sociedad les presenta; como para ampliar o reducir los horizontes de sus expectativas; como para no aceptar las prohibiciones o como para acatarlas (Reyes, 2006: 665).

De esta manera, al mismo tiempo que reconoce la fuerza del mandato de la feminidad y de sus usos y costumbres, también concibe una reivindicación de la igualdad ciudadana.

Luego toma al toro por los cuernos y expone:

En México, cuando pronunciamos la palabra mujer nos referimos a una criatura dependiente de una autoridad varonil. Ya sea la del padre, la del hermano, la del cónyuge, la del sacerdote. Sumisa a las decisiones ajenas, que regulan desde su aspecto personal hasta la elección del estado civil o de la carrera que va a estudiar o del trabajo al que se va a dedicar; adiestrada desde la infancia para comprender y tolerar los abusos de los más fuertes, pero también para restablecer el equilibrio interior tratando con mano fuerte a quienes se encuentran bajo su potestad, la mujer mexicana no se considera a sí misma —ni es considerada por los demás- como una mujer que haya alcanzado su realización si no ha sido fecunda en hijos, si no la ilumina el halo de la maternidad (Reyes, 2006: 665).

Y con su proverbial ironía plantea que el amor al hijo permite a quien lo siente: "Ascender, entre nubes de incienso, hasta las más altas cumbres de la abnegación" (2006: 666). Abnegación es una palabra que viene del latín, ab negare, y que significa negarse a sí misma. Rosario Castellanos reflexiona sobre ello y suelta entonces su atinada provocación: "La abnegación es la más celebrada de las virtudes de la mujer mexicana. Pero yo voy a cometer la impertinencia de expresar algo peor que una pregunta, una duda: la abnegación ies verdaderamente una virtud?" (2006: 666).

$\mathrm{Su}$ respuesta a esa inquietante pregunta pone en evidencia las consecuencias negativas de la abnegación, no sólo en la criatura sino también en otros integrantes de la familia:

Mas para la abnegación de la mujer mexicana no bastan los hijos. Se propina también a los demás miembros de la familia: al marido al que se convierte en un tirano doméstico quien, si no acierta a defenderse, se encuentra de pronto despojado hasta de la más mínima responsabilidad (Reyes, 2006: 667).

Al calificar de "loca" esa supuesta virtud Castellanos previene que:

[...] para su locura no existe entre nosotros otra camisa de fuerza más que la ley [...] Todas las disposiciones legales que hemos ido elaborando a lo largo de nuestra 
historia tienden a establecer la equidad — política, económica, educativa, social— entre el hombre y la mujer. Y no es equitativo $-\mathrm{y}$ por lo tanto tampoco es legítimo- que uno de los dos que forman la pareja dé todo y no aspire a recibir nada a cambio. No es equitativo — así que no es legítimo- que uno tenga la oportunidad de formarse intelectualmente y al otro no le quede más alternativa que la de permanecer sumido en la ignorancia. No es equitativo - y por lo mismo no es legítimo- que uno encuentre en el trabajo no sólo una fuente de riqueza sino también la alegría de sentirse útil, partícipe de la vida comunitaria, realizado a través de una obra, mientras que el otro cumple con una labor que no amerita remuneración y que apenas atenúa la vivencia de superfluidad y de aislamiento que se sufre; una labor, que por su misma índole perecedera, no se puede dar nunca por hecha. No es equitativo - y contraría el espíritu de la ley - que uno tenga toda la libertad de movimientos mientras el otro está reducido a la parálisis. No es equitativo - luego no es legal - que uno sea dueño de su cuerpo y disponga de él como se le dé la gana mientras el otro reserva ese cuerpo, no para sus propios fines, sino para que en él se cumplan procesos ajenos a su voluntad. No es equitativo el trato entre hombre y mujer en México (Reyes, 2006: 667).

La equidad es, justamente, la igualdad con reconocimiento de las diferencias. Resulta innovador y visionario el uso de Castellanos del término "equitativo". Ella denuncia: "Pero nos damos el lujo de violar la ley para seguir girando, como las mulas de noria, en torno a la costumbre. Aunque la ley se haya hecho, y lo sepamos, para corregir lo que la costumbre tiene de obsoleto, de viciado y de injusto" (2006: 667-668). No resbala al victimismoy, muy en su línea de criticar la complacencia femenina, lanza otra provocación:

Si la injusticia recae aún en las mujeres mexicanas, no tienen derecho a quejarse. Ellas lo han escogido así. Ellas han despreciado las defensas jurídicas que tienen a la mano. Ellas se niegan a asumir lo que los códigos les garantizan y la Constitución les concede: la categoría de personas (Reyes, 2006: 668).

Para terminar, cierra su discurso con un giro hacia un horizonte positivo:

Pero no hay por qué desesperar. Cada día una mujer —o muchas mujeres- (iquién puede saberlo puesto que lo que ocurre, ocurre en el anonimato, en la falta de ostentación, en la modestia?) gana una batalla para la adquisición y conservación de su personalidad. Una batalla que para ser ganada, requiere no solo de lucidez de la inteligencia, determinación en el carácter, temple moral, que son palabras mayores, sino también de otros expedientes como la astucia y, sobre todo, la constancia. Una batalla que al ganarse está gestando seres humanos más completos, uniones más felices, familias más armoniosas y una patria integrada por ciudadanos conscientes para quienes la libertad es la única atmósfera respirable y la justicia el suelo en el que arraigan y prosperan, y el amor el vínculo indestructible que los une (Reyes, 2006: 668).

La ovación estalla. El presidente Echeverría la felicita. María Esther Zuno la abraza, visiblemente conmocionada. El secretario de Educación, Víctor Bravo Ahuja, y el rector de la UNAM, Pablo González Casanova, se muestran un tanto desconcertados. Las mujeres asistentes al acto siguen aplaudiendo a rabiar y Rosario Castellanos, que acaba de poner una bomba expansiva en los cerebros de muchas de ellas, sonríe plácidamente.

Hoy en día sorprenden la vigencia y la radicalidad de su discurso, pero también abruma pensar que lo que ella analizó y denunció hace ya casi medio siglo, persiste todavía en las formas de actuar y de pensar de millones de mexicanas. La lectura de "La abnegación, una virtud loca" (Reyes, 2006: 663-668) es muy aleccionadora, pues con su tradicional lucidez, Rosario Castellanos rechaza el victimismo, reivindica la necesidad de terminar con la autocomplacencia femenina y propone que las mujeres se responsabilicen de sus vidas, que dejen de ser "parásitos". 
Ahora bien, después del discurso, la reflexión feminista de Rosario Castellanos se sigue expresando abiertamente en sus artículos periodísticos. Desde Tel Aviv -donde muere tres años después, en agosto de 1974- persiste en su crítica a la forma tradicional y enajenada de la feminidad. Una muestra: al develar los ejes argumentativos de sus tres cuentos y una novela corta que se encuentran en Álbum defamilia. Satisfacciónno pedida, aprovecha al personaje de Justina para discurrir una despiadada descripción de las mujeres enajenadas. Justina:

\section{[...] lo ignora todo en relación consigo misma y con quienes la rodean. Habita esa especie de limbo que constituye el ideal que persigue la educación femenina en nuestros días. La mujer que abandona ese limbo es para entrar en el infierno de la lucidez. Una lucidez que hay que graduar, que hay que disminuir, que hay que, definitivamente, aplastar. Pero que a veces insiste en renacer. $\mathrm{Y}$ de pronto hace el balance de una existencia entera en una sola palabra; farsante, fracasada, mediocre (Reyes, 2007: 62).}

Castellanos concluye su lapidaria descripción al recordar que, ya lo ha dicho Sartre, "el hecho de salvarse no es un asunto individual, es un asunto colectivo. Y dentro de una sociedad enajenada una de las criaturas más enajenadas, como lo es la mujer, no tiene acceso a la autenticidad, ni siquiera por la vía de la creación" (Reyes, 2007: 62).

Rosario Castellanos se desespera ante las abnegadas mujercitas mexicanas, a las cuales dirige sus saetas. En "Casa y potro... La señora avestruz hace su nido", con humor, se ríe de ella misma, y sigue asumiéndose feminista. Ya en su cargo de embajadora relata la incomodidad que siente ante las preguntas sobre asuntos domésticos que los otros diplomáticos le formulan: "Con una susceptibilidad hipersensibilizada por la experiencia yo empecé a sospechar que mis colegas reservaban, exclusivamente para mí, estos temas de conversación en vista de que soy mujer y... claro. ¿Antifeministas? Me pregunté afilando mis garras" (Reyes, 2007: 162). Luego comprueba que también entre los embajadores varones lo doméstico era un tema importante de conversación.

Desde Israel siguió preguntando por la ausencia de activismo feminista en nuestro país, e increpó a sus congéneres: "Usted, señora, abnegada mujercita mexicana; o usted, abnegada mujercita mexicana en vías de emancipación: ¿qué ha hecho por su causa en los últimos meses?" (Reyes, 2007: 195). En 1972, en "Bandera femenina: la liberación del amor", narra lo que está ocurriendo con las feministas en Estados Unidos, y pone en boca de una supuesta abnegada mujercita mexicana la creencia de que probablemente: “[...] el ejemplo de las norteamericanas sea imposible de seguir en México. iNuestra idiosincrasia es tan diferente! Y también nuestra historia y nuestras tradiciones. El temor al ridículo nos paraliza y entendemos muy bien al poeta francés cuando confiesa que 'por delicadeza, ha perdido la vida"' (2007: 195)..1

Su percepción tiene indudables resonancias con el ya mencionado "Feminismo 1970: curarnos en salud", donde dice: "Nosotras, al sur de la frontera del río Bravo, contemplamos la aventura desde lejos, como si el asunto no nos concerniera. Nos instala en esta certidumbre el hecho de que pertenecemos a otro país, a otro estilo de vida ipero tenemos razón en suponernos tan diferentes?" (Reyes, 2006: 380).

Por eso, luego señala que vale la pena pensar en lo que estaba pasando en Estados Unidos y comenzar a "curarse en salud" (2006: 381). La abnegada mujercita mexicana es su interlocutora imaginaria, e incluso Rosario Castellanos —en "Ni odio ni histeria: el estéril estallido emocional”, de 1972 - arroja otra de sus típicas provocaciones al confesar: "A mí me tentaba la imagen, nunca bien realizada, de abnegada madrecita mexicana" (Reyes, 2007: 219).

Antes de su etapa como embajadora en Israel, Rosario Castellanos ya encarnaba la representación nacional de la mujer pensante y la escritora. La lejanía de nuestro país le regaló una mayor libertad pues, como sugiere Monsiváis, ella "termina harta de los papeles y de las imposiciones culturales, decidida a la libertad a partir de la conducta y los gestos espontáneos" (1992: 323). 
Durante su labor como embajadora ella siguió mandando artículos rebosantes de aventuras personales y confesiones chuscas. Las referencias a sí misma persistieron, como en el texto "Entre pedir y dar: los caminos de la providencia", donde recapitula sobre su destino y escribe: "Yo era niña y vivía en Comitán, Chiapas, en pleno siglo XVI. Lo que daba por resultado que en mi futuro no había más que una sopa. Cuando yo fuera grande yo iba a ser mujer" (Reyes, 2007: 267).

En sus reflexiones feministas bullen sus vivencias personales, y Monsiváis, que comprende el valor de sus percepciones, la reivindica diciendo que "ella no confiesa, se limita a dar fe de que la intimidad no es vergonzosa ni inexpresable" (1992: 322). Pero además de mostrar aspectos de su intimidad, Castellanos elabora consideraciones políticas de una sutileza deslumbrante, como en "Juan Charrasqueado: tal día como hoy", cuando disipa cualquier duda sobre su postura respecto a los varones y señala que "[...] la posibilidad de igualar — desde el punto de vista no biológico sino puramente humano, por supuesto- a las mujeres con los hombres. Antes de meterme a averiguar si es posible, me gustaría estar segura si es deseable" (Reyes, 2007: 283). Ella rechaza tratar de parecerse a ese modelo de "hombre" cuyo sinónimo es el macho "porque es una empresa titánica que consume las energías enteras de la existencia y las vuelca íntegramente en el vacío" (2007: 283). Esa reflexión también es muy de avanzada, y hace una crítica justo a lo que hoy señalan los estudiosos sobre el costo que tiene para los varones cumplir con los mandatos de la masculinidad hegemónica.

En 1973, en un artículo sobre el feminismo en Israel, relata un desayuno con Golda Meir y otras mujeres diplomáticas, y vuelve a consignar su obsesión con la imposible conciliación de dos formas de vida: la del "hada del hogar" - las amas de casa, las abnegadas y sufridas madrecitas universales-y la del ser humano libre que elige una carrera para "realizarse y cumplirse" (Reyes, 2007: 343). Ahí mismo — "Feminismo en Israel: las golondrinas y el verano"- recuerda lo dicho por Betty Friedan sobre la sujeción doméstica y la mística de la feminidad, pero cuando analiza la situación de las mujeres en ese país, sus avances y sus obstáculos, y la comparara con el nuestro, dirá que en Israel "se respira mejor" (2007: 345). Sí, en Israel Rosario Castellanos vive un momento de plenitud. Luego de un susto terrible por una rara enfermedad infecciosa que tuvo a su hijo al borde de la muerte, en "Gabriel en el hospital: el valor de la vida" enuncia sucintamente su concepción de la felicidad y detalla: "la felicidad consiste en la coincidencia de lo que se quiere con lo que se debe y con lo que se puede" (Reyes, 2007: 286). No le duraría mucho esa afortunada coincidencia. De manera escalofriantemente premonitoria, un mes antes de morir electrocutada en su residencia diplomática al tratar de conectar una lámpara, escribe una frase estremecedora en "Decíamos ayer... Otra vuelta de tuerca": "Me quedé prendida de la lámpara” (Reyes, 2007: 381).

Rosario Castellanos es el paradigma de un ser humano brillante y crítico, encerrado en un cuerpo que lo limita socialmente, de la misma forma en que describe a sor Juana en "Agnon en Nepantla" (Reyes, 2007), como una de esas "criaturas que han sido registradas en una fecha pero que se mueven y son otras dimensiones temporales. A quienes constriñen un espacio y reclaman otro espacio diferente" (2007: 55). En uno de sus poemas más famosos, "Meditación en el umbral", Rosario hablará de su aspiración de alcanzar "otro modo de ser, humano y libre" (Castellanos, 1998a). Pero mientras llega a realizarse ese "otro modo de ser", ella oscila entre la señora decente y la feminista lúcida, entre la mujer desgarrada y la escritora famosa. Por eso, tal vez, en "De cómo hacerse famosa: a pesar de proponérselo" acepta: "Ya me acostumbré a permanecer en los umbrales" (Reyes, 2007: 377).

Elena Poniatowska comenta que uno de los entierros más tristes fue el de Rosario Castellanos en la Rotonda de los Hombres Ilustres del Panteón de Dolores, al cual acudieron Luis Echeverría y María Esther Zuno de Echeverría para acompañar al muy joven Gabriel Guerra Castellanos, hijo de la poeta con Ricardo Guerra. En agosto de 2017 se cumplirán 43 años de su muerte y su pensamiento sigue vivo, con palabras e ideas que nos conmueven e iluminan. Desde su tesis de la Facultad de Filosofía, Rosario Castellanos se propuso entender a 
esas pocas y excepcionales mujeres que optan por "otro modo de ser", para:

[...] comprenderlas, averiguar por qué se separaron del resto del rebaño e invadieron un terreno prohibido y, más que ninguna otra cosa, qué las hizo dirigirse a la realización de esta hazaña, de dónde extrajeron la fuerza para modificar sus condiciones naturales y convertirse en seres aptos para labores que, por lo menos, no les son habituales (2005: 85-86).

Probablemente no imaginó que ella también sería excepcional, que se "separaría del resto del rebaño" y que realizaría una hazaña literaria, de una riqueza y fuerza descomunal.

Hoy el legado crítico de Rosario Castellanos se perfila también como un punteo necesario en la agenda ético-política del feminismo mexicano. Entre las varias tareas que ella esbozó destacan dos: la de la autocrítica implacable para evitar la abnegación, el mujerismo y el victimismo, y la de la asunción de un feminismo lúcido y radical — que va a la raíz - y que, al visualizar los costos que tiene la masculinidad, es capaz también de incluir a los varones. Y si bien en la actualidad su nombre concita respeto y asombro, no dejo de lamentar que Rosario Castellanos debió de haberse sentirdo sola, muy sola, en su lúcido e inteligente feminismo.

\section{Notas}

${ }^{1}$ Este no es un análisis literario sino, como su título indica, un acercamiento al feminismo de Rosario Castellanos a partir de algunos de sus textos.

${ }^{2}$ En el prólogo a la recopilación de artículos periodísticos que José Emilio Pacheco preparó pocos meses antes de la muerte de Castellanos.

${ }^{3}$ Este dato lo consigna Andrea Reyes, en su entrevista con Dolores Castro, la gran amiga de Rosario (2013: 165).

${ }^{4}$ Amigos de Castellanos y estudiosos de su obra coinciden en destacar su característica ironía (ver como ejemplos, Megged, 1984 y Amador, 2006).
${ }^{5}$ De ellos, algunos más largos fueron publicados en el "Diorama de la Cultura" de Excélsior, en la Revista de la Universidad Nacional Autónoma de México y en Suma Bibliográfica.

6 "Por mujerismo entendemos la idea de que las mujeres, por el hecho de serlo, poseen ciertas virtudes que las hacen mejores que los hombres. No es mujerismo el hecho de dar prioridad política a las mujeres, sino concepciones reduccionistas y sectarias según las cuales sólo las mujeres son capaces de cierto tipo de acción y por eso sólo hay que trabajar con mujeres, 'las verdaderas portadoras del cambio revolucionario'. Esta diferencia, por sencilla que parezca, es fundamental. Puesto que las mujeres, como grupo social —como género-, están en condiciones singulares de discriminación, opresión y explotación, es correcto plantearse un trabajo específico con ellas [...] al rechazar la idea de la 'esencia femenina' [del mujerismo] pensamos que el tema del feminismo no son las mujeres, sino las relaciones entre el género femenino y [el] masculino" (Lamas, 1990).

${ }^{7}$ Cuyo autor o autora es M. Loreto H., de quien Rosario asegura no tener idea de si se trata de una mujer o de un hombre (Reyes, 2004: 247).

${ }^{8}$ Acevedo viajó a California para atestiguar la marcha en San Francisco. Su reportaje se publicó con el título "Nuestro sueño está en escarpado lugar" el 30 de septiembre 1970, y se republicó en la revista Debate Feminista (Acevedo, 1995).

${ }^{9}$ Marta Acevedo relata ese episodio en "Lo volvería a elegir" (1995b).

${ }^{10}$ Las otras tres oradoras participantes fueron Margarita Lainé de Zubiría, la senadora Aurora Ruvalcaba y la sinaloense Aurora Arrayales Sandoval. A Rosario Castellanos la nombran "la poetisa". El Universal, 16 de febrero 1971.

"Alude al poema Chanson de la plus haute tour (Canción desde la torre más alta), de Arthur Rimbaud (18541891): Oisive jeunesse/A tout asservie,/Par délicatesse/J'ai perdu ma vie (Juvenil pereza/a todo sujeta,/por delicadeza,/he perdido mi vida).

\section{Referencias blibliográgicas}


Acevedo, Marta (1995a). “Nuestro sueño está en escarpado lugar”. En Debate Feminista 12, octubre: 355-370.

Acevedo, Marta (1995b). "Lo volvería a elegir". En Debate Feminista 12, octubre: 3-15.

Ahern, Maureen (1988). "Introduction". En M. Ahern (ed.), A Rosario Castellanos Reader. Austin: University of Texas.

Amador, Diana (2006). "Las grandes calumnias no se hacen sin fundamento. Ironía y extrañamiento en El eterno femenino de Rosario Castellanos". En R. Zamudio, Luz Elena y Margarita Tapia Arizmendi (eds.), Rosario Castellanos.DeComitána Jerusalén. México: ITESM-Campus Toluca, FONCA-CONACULTA, UAEM, Bonobos Editores.

Bourdieu, Pierre (2000). La dominación masculina. Barcelona: Anagrama.

Cano, Gabriela (1992). "Rosario Castellanos: entre preguntas estúpidas y virtudes locas”. En Debate Feminista, 6, septiembre: 253-259.

Cano, Gabriela (2012). "Sobre cultura femenina de Rosario Castellanos". En Rosario Castellanos, Sobre cultura femenina. México: FCE.

Castellanos, Rosario (1989). “Álbum de familia”. En Obras I (narrativa). México: FCE.

Castellanos, Rosario (1998a). "Meditación en el umbral". En Otros poemas, Obras II. México: FCE.

Castellanos, Rosario (1998b). "Pasaporte". En Viaje redondo, Obras II. México: FCE.

Castellanos, Rosario (1998c). "Otra vez sor Juana”. En Juicios sumarios, Obras II. México: FCE.

Castellanos, Rosario (2005). Sobre cultura femenina. México: FCE.

Dalla Costa, Mariarosa y Selma James (1975). El poder de la mujer y la subversión de la comunidad. México: Siglo XXI.

Franco, Jean (1994). Las conspiradoras. La representación de la mujer en México. México: FCE.

García Flores, Margarita (1979). "Rosario Castellanos: la lucidez como forma de vida”. En Cartas marcadas. México: Difusión Cultural-UNAM.

Lamas, Marta (1990). "Editorial". En Debate Feminista, 1, marzo.

Lamas, Marta (2016). "Género". En Hortensia Moreno y
Eva Alcántara (coords.), Conceptos clave en los estudios de género, t. 1. México: Programa Universitario de Estudios de Género-UNAM, pp. 151-171.

Megged, Nahum (1984). Rosario Castellanos. Un largo camino a la ironía. México: COLMEX,

Mejía, Eduardo (1998). "Rosario Castellanos, la voz del extranjero", prólogo al t. II de Obras (poesía, teatro y ensayo). México: FCE.

Monsiváis, Carlos (1992). "La enseñanza del llanto". En Debate Feminista 6, septiembre.

Pacheco, José Emilio (1974). "La palabra", prólogo en Rosario Castellanos, El uso de la palabra. México: Ediciones de Excélsior.

Poniatowska, Elena (1980). "Yosoy denacimiento cobarde. He temido muchas cosas, pero lo que he temido más es la soledad”. En La Cultura en México, 947, suplemento de la revista Siempre!, I de mayo. Reproducido en Debate Feminista, 6, septiembre de 1992.

Poniatowska, Elena (2004). "Castellanos, precursora del feminismo en México” I y II. En La Jornada, 12 y 13 de septiembre.

Poniatowska, Elena (s.f.) "Escribir; mea culpa, mea culpa" [documento inédito].

Pratt, Mary Louise (2000). "No me interrumpas: las mujeres y el ensayo latinoamericano". En Debate Feminista, 21, abril.

Reyes, Andrea H. (comp.) (2004). Mujer de palabras. Artículos rescatados de Rosario Castellanos, t. I, México: CONACULTA.

Reyes, Andrea H. (2006). Mujer de palabras. Artículos rescatados de Rosario Castellanos, t. II, México: CONACULTA.

Reyes, Andrea H. (2007). Mujer de palabras. Artículos rescatados de Rosario Castellanos, t. III. México: CONACULTA.

Reyes, Andrea H. (2013). Recuerdo, recordemos. Ética y política en Rosario Castellanos. México: Universidad Autónoma de Chiapas.

Zamudio, Luz Elena y Margarita Tapia A. (eds.) (2006). Rosario Castellanos. De Comitán a Jerusalén. México: ITESM-Campus Toluca, FONCA-CONACULTA, UAEM, Bonobos Editores. 